\title{
Optimal Allocation of DSTATCOM in Distribution Network Using Whale Optimization Algorithm
}

\author{
P. Balamurugan \\ Department of Electrical and Electronics \\ Engineering, Saveetha School of \\ Engineering, Saveetha Institute of \\ Medical and Technical Sciences, \\ Chennai, India \\ mrbalap@gmail.com
}

\author{
T. Yuvaraj \\ Department of Electrical and Electronics \\ Engineering, Saveetha School of \\ Engineering, Saveetha Institute of \\ Medical and Technical Sciences, \\ Chennai, India \\ yuvaraj4252@gmail.com
}

\author{
P. Muthukannan \\ Department of Electrical and Electronics \\ Engineering, Saveetha School of \\ Engineering, Saveetha Institute of \\ Medical and Technical Sciences, \\ Chennai, India \\ muthukannan@saveetha.com
}

\begin{abstract}
This paper deals with a new approach implemented to decrease power losses and improve voltage profile in distribution networks using Distribution STATic COMpensator (DSTATCOM). DSTATCOM location can be determined by the voltage stability index (VSI) and sizing can be identified by nature inspired, recently developed whale optimization algorithm (WOA). To check efficacy, the proposed technique is tested on two standard buses: Indian rural electrification 28-bus and IEEE 69-bus distribution systems. Obtained results show that optimal allocation of DSTATCOM effectively reduces power losses and improves voltage profile.
\end{abstract}

Keywords-whale optimization algorithm (WOA); voltage stability index (VSI); Distribution STATic COMpensator (DSTATCOM); radial distribution system (RDS)

\section{INDRODUCTION}

High $\mathrm{R} / \mathrm{X}$ ratio in distribution networks causes poor power quality in a distribution system [1]. Its major drawbacks are voltage drop, lagging power factor and instability. These issues create large power losses, poor voltage profile and create network security problems in rural distribution network (RDS). In total power generation $10-13 \%$ is consumed as losses in distribution [2-6]. Aforesaid problems can be resolved by adequate reactive power injection in the distribution system. The reactive power can be injected in the RDS with the help of compensating devices. So, compensating devices are essential in the distribution system to decrease power losses and increase the voltages between buses [7]. The majorly of compensating devices used in the RDS are shunt capacitors, regulators, UPFC, SSSC, and DSTATCOM [8]. DSTATCOMs have many advantages over other compensating devices, like low power losses, less harmonic production, compact size and low cost. In addition, they will not create any operation problems like resonance or harmonics [9]. A DSTATCOM consists of a shunt connected voltage source converter (VSC) which is capable, by compensating the bus voltage, to provide enhanced power factor and reactive power compensation in the RDS. A new strategy can be designed for determining the location and size of DSTATCOM to reduce system power loss, improve voltage profile, power factor, load balancing and power quality, free from distribution line overloading, enhance system stability, decrease pollutant emissions, and increase system efficiency [10].

Several optimization techniques and compensating devises have been introduced to reduce power loss in the distribution side via optimal DSTATCOM placement: Immune algorithm (IA), differential evolution algorithm (DEA), particle swarm optimization (PSO), genetic algorithm (GA), bat algorithm (BA), harmony search algorithm (HSA) [7-13]. Whale optimization algorithm (WOA) has not yet been utilized for finding the location of DSTATCOM in the RDS. In this work DSTSTCOM is introduced for reducing total power loss in RDS by using the WOA. This proposed optimization algorithm is developed on the activities and performance behavior of the whales. WOA is effectively utilized for finding the optimal size and location of the DSTATCOM in a distribution network. This biological based algorithm effectively reduces the exploration area. This method is tested on standard 28-bus and 69-bus test systems by considering minimization loss and voltage stability enhancement. Obtained results by WOA are compared with the results taken from IA and GA. When compared to these existing algorithms, WOA effectively reduces losses and increases voltage stability.

\section{PROBLEM FORMULATION}

Newton-Raphson, Gauss-Seidal and fast decoupled are a few classical load flow methods, which are not suitable in identifying the line flows and voltages in distribution networks because of the high resistance by reactance ratio $(\mathrm{R} / \mathrm{X})$ of the distribution system. So, the forward-backward sweep distribution load flow is used in the present work to solve the load flow [15]. At node $t$, the equivalent injected current is specified as:

$$
I_{t}=\left(\frac{P_{t}+Q_{t}}{V_{t}}\right)
$$

By applying Kirchhoff's current law amongst the buses $t$ and $t+1$ in line section, the branch current is set as:

$$
J_{t, t+1}=I_{t+1}+I_{t+2}
$$


By the usage of bus injected in the direction of branch current matrix (BIBC), (2) is resulted into matrix format:

$$
|J|=|B I B C||I|
$$

For calculation of voltage at buses $t+1$, Kirchhoff's voltage law is employed and the equation is specified as:

$$
V_{t+1}=V_{t}-J_{t, t+1}\left(R_{t, t+1}+j X_{t, t+1}\right)
$$

In the middle of line section buses $t$ and $t+1$, the real reactive power loss will be computed as:

$$
\begin{aligned}
& P_{\text {Loss }(t, t+1)}=\left(\frac{P_{t, t+1}^{2}+Q_{t, t+1}^{2}}{\left|V_{t, t+1}\right|^{2}}\right) * R_{t, t+1} \\
& Q_{\text {Loss }(t, t+1)}=\left(\frac{P_{t, t+1}^{2}+Q_{t, t+1}^{2}}{\left|V_{t, t+1}\right|^{2}}\right) * X_{t, t+1}
\end{aligned}
$$

Total power loss $P_{\text {TLoss }}$ in the system is calculated by summing up of all losses in every line section:

$$
P_{\text {TLoss }}=\sum_{t=1}^{n b} P_{(\text {Loss }, t, t+1)}
$$

\section{A. Objective Function}

Objective function's mathematical formulation is stated as:

$$
\operatorname{Min}(F)=\min \left(\frac{P_{\text {loss }}}{V S I}\right)
$$

where $P_{T, l o s s}$ is the total power loss of the radial distribution system.

\section{B. Constraints}

Additional inequality constraints are also considered for this problem. These are:

\section{1) Voltage Deviation Limit:}

$$
V_{t}^{\min } \leq\left|V_{t}\right| \leq V_{t}^{\max }
$$

where $V_{t}^{\min }$ and $V_{t}^{\max }$ are the minimum and maximum voltage limits at bus $t$, respectively.

\section{2) Reactive Power Compensation:}

$$
\begin{aligned}
& Q_{D S T A T C O M(t)}^{\min } \leq Q_{\text {DSTATCOM }(t)} \leq Q_{\text {DSTATCOM }(t)}^{\max } \\
& t=1,2, \ldots . ., n b
\end{aligned}
$$

where $Q_{\text {DSTATCom( } t)}^{\min }$ and $Q_{\text {DSTATCom( } t)}^{\max }$ are the minimum and maximum reactive power limits at bus $t$, respectively.

\section{Voltage Stability Index}

In order to discover the node, VSI is used. At each node, voltage stability is calculated with the aid of (11). The less significance VSI node will be the appropriate locality for the employment of DSTATCOM [16]. To avoid the probabilities of voltage collapse, VSI will be maximized.

$$
\begin{aligned}
& \operatorname{VSI}(m+1)=\left|V_{m}\right|^{2}-4\left[\begin{array}{c}
P_{m+1, e f f} * X_{m}- \\
Q_{m+1, e f f} * R_{m}
\end{array}\right]^{2} \\
& -4\left[P_{m+1, e f f}+R_{m} * Q_{m+1}+X_{m}\right]\left|V_{m}\right|^{2}
\end{aligned}
$$

\section{WHALE OPTIMIZATION ALGORITHM}

WOA is a biological based optimization algorithm which is developed on humpback $\mathrm{X}$ behavior of whales. Certain brain cells of whales and human beings are similar. The special behavior of whales in search for food is called bubble-net feeding method. The searching method is based on creating bubbles by encircling or through a ' 9 '-shaped path. This behavior of searching is derived mathematically by two phases [17]:

\section{A. Searching and Encircling Prey}

Searching prey can be modeled by (12) and (13), where variables $A$ and $C$ are coefficient vectors denoted as in (14) and (15):

$$
\begin{aligned}
& D=\left|C \cdot X_{\text {rand }}-X\right| \\
& X(t+1)=X_{\text {rand }}-A \cdot D \\
& A=2 \cdot a \cdot r-a \\
& C=2 \cdot r
\end{aligned}
$$

where $\alpha$ is linearly decreasing from 2 to 0 and $r$ is a random number between $[0,1]$.

$$
\begin{aligned}
& D=\left|C \cdot X^{*}(t)-X(t)\right| \\
& X(t+1)=X^{*}(t)-A . D
\end{aligned}
$$

If $A \geq 1$, searching prey, denoted by (12) and (23), otherwise encircling prey, by shrinking mechanism denoted by (16) and (17), are used, where $t$ is the current iteration, $X$ is the position vector and $X^{*}$ is the best value of the position vector so far.

\section{B. Spirally Updating Position}

Position updating is denoted by (18):

$$
X(t+1)=\left\{\begin{array}{l}
X^{*}(t)-A . D, \text { if } p>0.5 \\
D . e^{b l} \cdot \operatorname{Cos} 2 \pi I+X^{*}(t), \text { if } p \leq 5
\end{array}\right.
$$

where $p$ is a random number between $[0,1], l$ is between $[-1,1]$ and $b$ is constant for describing the spiral shape [18].

\section{Proposed Work Implementation}

WOA approach to reduce power losses and enhance voltage profile by placing DSTATCOM optimally in the network is described by the following steps:

- Step 1: Set load data and bus data.

- Step 2: Estimate the total power loss, VSI and bus voltages using forward-backward sweep method.

- Step 3: Read line and load data of the system and solve the feeder-line flow for the system using load flow method.

- Step 4: Find the best DSTATCOM locations using VSI.

- Step 5: Set the population/solutions itmax=100, number of DSTATCOM locations $d=1$, DSTATCOM Min=20, DSTATCOM Max=2000

- Step 6: Generate the population of DSTATCOM sizes randomly using : 
Population $=\left(\mathrm{DST}_{\max }-\mathrm{DST}_{\min }\right) \times \operatorname{rand}()+\mathrm{DST}_{\min }$

where $\mathrm{DST}_{\max }$ and $\mathrm{DST}_{\text {min }}$ are minimum and maximum limits of DSTATCOM sizes.

- Step 7: Find power losses for generated population.

- Step 8: Current best solution is DSTATCOM values with low losses.

- Step 9: Whales position can be updated through (13) - (15)

- Step 10: From updated population, losses can be determined, by load flow method.

- Step 11: If acquired losses are less, then substitute with current best solution or else repeat step 9 .

- Step 12: Display the results if maximum iterations number is reached.

\section{RESULTS AND DISCUSSION}

In this paper, WOA is implemented for 28-bus and 69-bus systems. In these test systems, three different cases are analyzed to show the effectiveness of the proposed method as shown in Tables I and II, namely a system without DSTATCOM, system with single DSTATCOM, and system with multiple DSTATCOMs. To show the advantage of WOA, the simulation results of WOA are matched with the ones from other existing optimization methods. The results produced by WOA are better than the ones acquired with other optimization methods.

\section{A. 28-Bus Indian Rural Distribution Network}

To evaluate the capability of the proposed method in real time systems, an $11 \mathrm{kV}, 28$-bus rural Indian distribution system has been taken and tested. The network is radial in nature with 28 buses and the substation linked at first bus as displayed in Figure 1. Essential load and bus data of power lines are taken from [19].

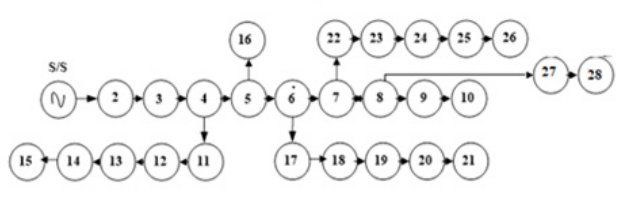

Fig. 1. One line diagram of 28-bus Indian distribution network

\section{1) Case (i) System without DSTATCOM}

The initial power losses without using any DSTATCOM in the radial network are $68.88 \mathrm{~kW}$. Performance analysis of the 28-bus test system in terms of power losses and voltage stability index with and without DSTATCOM are displayed in Table I.

\section{2) Case (ii) System with Single DSTATCOM.}

By this process, the $7^{\text {th }}$ bus is designated as an optimal DSTATCOM installation and the optimal place of this location can be designed through WOA. The power losses are reduced to $36.89 \mathrm{~kW}$ from $68.88 \mathrm{~kW}$ and the voltage profile is greatly improved. The least bus voltage is obtained by placing single DSTATCOM is 0.9472 p.u.

\section{3) Case (iii) System with Multiple DSTATCOMs}

By this process, two DSTATCOMs are optimally placed and sized at $7^{\text {th }}$ and $12^{\text {th }}$ bus. From Table I, it is observed that power loss reduction and voltage stability enhancement are high in multiple DSTATCOM placement compared with single DSTATCOM placement. Power losses are reduced to $33.75 \mathrm{~kW}$ and the VSI is improved to $0.8035 \mathrm{p} . \mathrm{u}$ with multiple DSTATCOM placement. Also the minimum bus voltage enhanced from 0.9123p.u to 0.9495p.u. Figure 2 shows the voltage profile improvement of 28-bus with and without single and multiple DSTATCOM placement. The voltage profile is greatly improved with the placement of multiple DSTATCOM's compared to single DSTATCOM placement. We did not compare the proposed method with existing ones, since there is no work available with DSTATCOM placement for 28-bus system in the related literature.

TABLE I. 28-BUS TEST SYSTEM PERFORMANCE ANALYSIS

\begin{tabular}{|c|c|c|}
\hline \multicolumn{3}{|c|}{ Proposed Method } \\
\hline \multirow{4}{*}{$\begin{array}{l}\text { Case (i): Without } \\
\text { Compensation }\end{array}$} & $\mathrm{P}_{\text {loss }}(\mathrm{kW})$ & 68.88 \\
\hline & CVD & 1.7975 \\
\hline & $\mathrm{VSI}_{\min }(\mathrm{p} . \mathrm{u})$ & 0.6927 \\
\hline & $\mathrm{V}_{\min }(\mathrm{p} . \mathrm{u})$ & 0.9123 \\
\hline \multirow{6}{*}{$\begin{array}{c}\text { Case (ii): With } \\
\text { single DSTATCOM }\end{array}$} & Size in kVAr (location) & $580(7)$ \\
\hline & $\mathrm{P}_{\text {loss }}(\mathrm{kW})$ & 36.89 \\
\hline & $\% \mathrm{P}_{\text {loss }}$ Reduction & 46.44 \\
\hline & Total CVD & 0.3093 \\
\hline & $\mathrm{VSI}_{\min }(\mathrm{p} . \mathrm{u})$ & 0.7999 \\
\hline & $\mathrm{V}_{\min }(\mathrm{p} . \mathrm{u})$ & 0.9472 \\
\hline \multirow{6}{*}{$\begin{array}{c}\text { Case (iii): With } \\
\text { Multiple } \\
\text { DSTATCOMs }\end{array}$} & Size in kW (location) & $480(7), 230(12)$ \\
\hline & $\mathrm{P}_{\text {loss }}(\mathrm{kW})$ & 33.75 \\
\hline & $\% \mathrm{P}_{\text {loss }}$ Reduction & 51 \\
\hline & TVD & 0.2076 \\
\hline & $\mathrm{VSI}_{\min }(\mathrm{p} . \mathrm{u})$ & 0.8035 \\
\hline & $\mathrm{V}_{\min }(\mathrm{p} . \mathrm{u})$ & 0.9495 \\
\hline
\end{tabular}

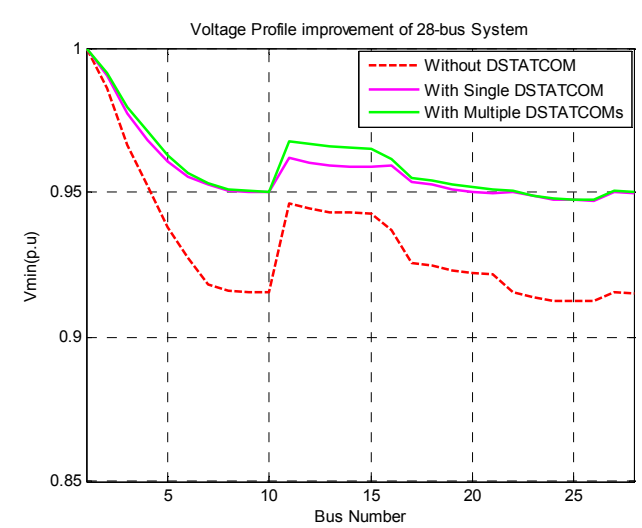

Fig. 2. Voltage profile improvement of 28-bus

\section{B. IEEE 69-Bus Distribution Network}

To evaluate WOA in a high level system, an $11 \mathrm{kV}$, IEEE 69-bus has been taken and tested. The required load and bus 
data of power lines are taken from [9]. The real and reactive load are $3801 \mathrm{~kW}$ and $2694.6 \mathrm{kVAr}$ and the base values are 100MVA, 12.66KV. The real and reactive power losses of the base case are $225 \mathrm{~kW}$ and $102.2 \mathrm{kVAr}$. The one line diagram of IEEE 69-bus is depicted in Figure 3. Performance analysis of the IEEE 69-bus test system with and without compensation in terms of power losses, $\mathrm{kVAr}$, VSI, and voltage profile is shown in Table II.

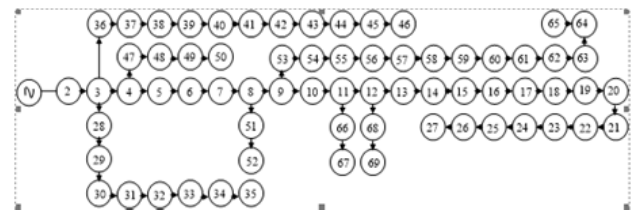

Fig. 3. One line diagram of IEEE 69-bus

TABLE II. 69-BUS TEST SYSTEM PERFORMANCE ANALYSIS

\begin{tabular}{|c|c|c|c|c|}
\hline & & \begin{tabular}{|c|} 
Proposed \\
Method \\
\end{tabular} & IA [9] & GA [9] \\
\hline \multirow{4}{*}{$\begin{array}{l}\text { Case (i): Without } \\
\text { Compensation }\end{array}$} & $\mathrm{P}_{\text {loss }}(\mathrm{kW})$ & 225 & 225 & 225 \\
\hline & Total CVD & 0.7327 & 0.7327 & 0.7327 \\
\hline & $\mathrm{VSI}_{\min }$ (p.u) & 0.6822 & 0.6822 & 0.6822 \\
\hline & $\mathrm{V}_{\min }(\mathrm{p} . \mathrm{u})$ & 0.9090 & 0.9090 & 0.9090 \\
\hline \multirow{6}{*}{$\begin{array}{c}\text { Case (ii): With } \\
\text { single DSTATCOM }\end{array}$} & $\begin{array}{l}\text { Size in } \mathrm{kVAr} \\
\text { (location) }\end{array}$ & $1300(61)$ & $1704(61)$ & $1928(61)$ \\
\hline & $\mathrm{P}_{\text {loss }}(\mathrm{kW})$ & 151.09 & 157.50 & 165.43 \\
\hline & $\% \mathrm{P}_{\text {loss }}$ Reduction & 32.84 & 30 & 26.47 \\
\hline & Total CVD & 0.5162 & (n--- & $\begin{array}{l}----- \\
--\end{array}$ \\
\hline & $\mathrm{VSI}_{\min }(\mathrm{p} . \mathrm{u})$ & 0.7584 & 0.7561 & 0.7534 \\
\hline & $\mathrm{V}_{\min }(\mathrm{p} . \mathrm{u})$ & 0.9389 & 0.9353 & 0.9380 \\
\hline \multirow{6}{*}{$\begin{array}{c}\text { Case (iii): With } \\
\text { Multiple } \\
\text { DSTATCOMs }\end{array}$} & Size in $\mathrm{kW}$ (location) & \begin{tabular}{|l|}
$350(17)$ \\
$1250(61)$ \\
\end{tabular} & --- & --- \\
\hline & $\mathrm{P}_{\text {loss }}(\mathrm{kW})$ & 146.34 & -- & -- \\
\hline & $\% \mathrm{P}_{\text {loss }}$ Reduction & 34.96 & --- & -- \\
\hline & Total CVD & 0.5011 & --- & -- \\
\hline & $\mathrm{VSI}_{\min }(\mathrm{p} . \mathrm{u})$ & 0.7630 & -- & --- \\
\hline & $\mathrm{V}_{\min }(\mathrm{p} . \mathrm{u})$ & 0.9417 & -- & --- \\
\hline
\end{tabular}

\section{1) Case (i) System without DSTATCOM}

The initial power loss without any compensation is $225 \mathrm{~kW}$.

2) Case (ii) System with single DSTATCOM.

In this process, the $61^{\text {st }}$ bus is designated for optimal DSTATCOM installation using VSI and the optimal placing of this location can be designed through WOA. The real power loss in this case is reduced to $151.09 \mathrm{~kW}$. The minimum bus voltage obtained from this case is 0.9299 p.u.

\section{3) Case (iii) System with Multiple DSTATCOMs}

In this test case, DSTATCOMs are optimally placed and sized at $17^{\text {th }}$, and $61^{\text {th }}$ buses. From Table II, it is observed that power loss reduction and voltage stability enhancement are high in multiple DSTATCOM placement compared with single DSTATCOM placement. The power loss is reduced to
$34.96 \mathrm{~kW}$ which is high compared with case (ii). The stability value of the system is improved from 0.6822p.u to 0.7630p.u. To show its effectiveness, the proposed WOA is compared with IA and GA [9]. It could be concluded that the proposed WOA gives better loss reduction, stability improvement and voltage enhancement compared with existing algorithms.

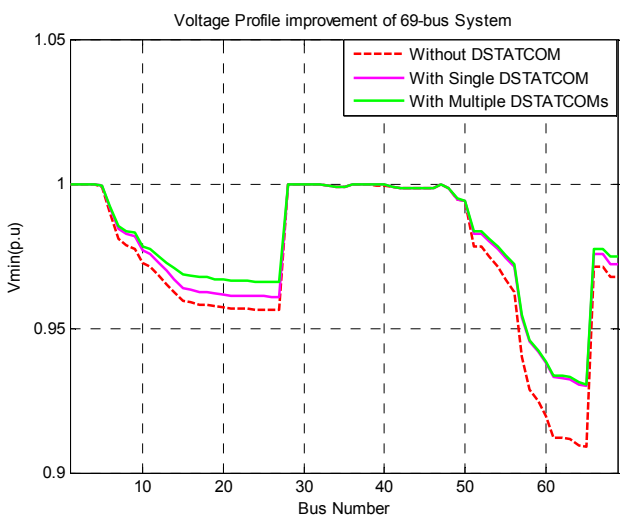

Fig. 4. Voltage profile improvement of 69-bus system

\section{CONCLUSION}

Whale optimization algorithm has been implemented and tested in Indian 28-bus and IEEE 69-bus radial distribution systems. To find the optimal location of the DSTATCOM, VSI method was used. To find optimal size of DSTATCOM, WOA was used. The power loss was reduced and voltage profile was improved. The proposed method resulted in better power loss reduction and improved the voltage profile than other existing techniques. Hence, the proposed method can be implemented for any distribution system to reduce power loss and enhance voltage profile.

\section{REFERENCES}

[1] T. Yuvaraj, K. Ravi, K. R. Devabalaji, "DSTATCOM Allocation in the Radial Distribution Network with Different Stability Indices using Bat Algorithm", Ain Shams Engineering Journal, Vol. 8, No. 3, pp. 391-403, 2017

[2] T. Yuvaraj, K. Ravi, K. R. Devabalaji, "Optimal allocation of DG and DSTATCOM in radial distribution system using cuckoo search optimization algorithm", Modelling and Simulation in Engineering, Vol. 2017, Article ID 2857926, 2017

[3] K. Somsai, T. Kulworawanichpong, "Modeling, simulation and control of D-STATCOM using ATP/EMTP”, IEEE 13th International Conference on Harmonics and Quality of Power, Wollongong, NSW, Australia, September 28 - October 1, 2008

[4] C. Sumpavakup, T. Kulworawanichpong, "Distribution voltage regulation under three-phase fault by using D-STATCOM", International Journal of Electrical and Computer Engineering, Vol. 2, No. 11, pp. 2492-2496, 2008

[5] B. M. Repalle, K. M. Rosalina, N. P. Kumar, "Fuzzy logic based optimal location and sizing of DSTATCOM in radial distribution systems", International Journal of Advanced Technology in Engineering and Science, Vol. 2, No. 8, pp. 122-129, 2014

[6] G. Ledwich, A. Ghosh, "A flexible DSTATCOM operating in voltage or current control mode", IEE Proceedings-Generation, Transmission and Distribution, Vol. 149, No. 2, pp. 215-224, 2002

[7] I. Wasiak, R. Mienski, R. Pawelek, P. Gburczyk, "Application of DSTATCOM compensators for mitigation of power quality disturbances 
in low voltage grid with distributed generation", IEEE 9th International Conference on Electrical Power Quality and Utilisation, Barcelona, Spain, October 9-11, 2007

[8] S. Jazebi, S. H. Hosseinian, B. Vahidi, "DSTATCOM allocation in distribution networks considering reconfiguration using differential evolution algorithm", Energy Conversion and Management, Vol. 52, No.7, pp. 2777-2783, 2011

[9] S. A. Taher, S. A. Afsari, "Optimal location and sizing of DSTATCOM in distribution systems by immune algorithm", International Journal of Electrical Power \& Energy Systems, Vol. 60, pp. 34-44, 2014

[10] S. Devi, M. Geethanjali, "Optimal location and sizing determination of Distributed Generation and DSTATCOM using Particle Swarm Optimization algorithm", International Journal of Electrical Power \& Energy Systems, Vol. 62, pp. 562-570, 2014

[11] Y. Del Valle, J. C. Hernandez, G. K. Venayagamoorthy, R. G. Harley, "Multiple STATCOM allocation and sizing using particle swarm optimization", IEEE PES Power Systems Conference and Exposition, Atlanta, USA, October 29-November 1, 2006

[12] T. Yuvaraj, K. Ravi, K. R. Devabalaji, "Optimal placement and sizing of DSTATCOM using harmony search algorithm”, Energy Procedia, Vol. 79, pp. 759-765, 2015

[13] A. Bagherinasab, M. Zadehbagheri, S. A. Khalid, M. Gandomkar, N. A. Azli, "Optimal placement of D-STATCOM using hybrid genetic and ant colony algorithm to losses reduction", International Journal of Applied Power Engineering, Vol. 2, No. 2, pp. 53-60, 2013

[14] K. R. Devabalaji, A. M. Imran, T. Yuvaraj, K. Ravi, "Power loss minimization in radial distribution system", Energy Procedia, Vol. 79, pp. 917-923, 2015

[15] P. Balamurugan, Y. Apoorva, T. Yuvaraj, P. Muthukannan "DSTATCOM Allocation in Radial Distribution Networks Using Novel Fruit Fly Algorithm", Journal of Advanced Research in Dynamical and Control Systems, No. 8 (special), pp. 1470-1478, 2018

[16] Y. Thangaraj, R. Kuppan, "Multi-objective simultaneous placement of DG and DSTATCOM using novel lightning search algorithm", Journal of Applied Research and Technology, Vol. 15, No. 5, pp. 477-491, 2017

[17] S. Mirjalili, A. Lewis, "The whale optimization algorithm", Advances in Engineering Software, Vol. 95, pp. 51-67, 2016

[18] D. B. Prakash, C. Lakshminarayana, "Optimal siting of capacitors in radial distribution network using whale optimization algorithm", Alexandria Engineering Journal, Vol. 56, No. 4, pp. 499-509, 2017

[19] S. Gupta, G. Brar, "An Efficient GA Method for Optimal Capacitor Placement in Radial Distribution System", Acta Electrotehnica, Vol. 51, No. 4 , pp. $243-247,2010$ 